\title{
Reassessment of the invasion history of two species of Cakile (Brassicaceae) in Australia
}

\author{
Roger D. Cousens, Peter K. Ades, Mohsen B. Mesgaran and Sara Ohadi \\ Melbourne School of Land \& Environment, The University of Melbourne, Victoria, 3010, AUSTRALIA
}

\begin{abstract}
In this paper we revisit the invasion history of two species of Cakile in Australia. Cakile edentula subsp. edentula arrived in the mid $19^{\text {th }}$ Century and spread into coastal strandline habitat from the southeast towards the west and to the north; Cakile maritima arrived in the late $19^{\text {th }}$ Century and has replaced Cakile edentula over much of the range. While Cakile edentula is morphologically quite uniform, the great variation within Cakile maritima has confused field ecologists. Using herbarium records we update previous accounts of the spread of the species and report on field surveys that determined their current geographic overlap in Tasmania and in northern New South Wales/southern Queensland. We examine regional morphological variation within Cakile maritima using the national herbaria collections and variation within new population samples. We support previous interpretations that Cakile maritima has been introduced on more than one occasion from morphologically distinct races, resulting in regional variation within Australia and high variability within populations in the south-east. Western Australian populations appear distinct and probably did not initiate those in the east; we consider that eastern populations are likely to be a mix of Cakile maritima subsp. maritima from the Mediterranean and Cakile maritima subsp. integrifolia from Atlantic Europe. Although introgression from Cakile edentula into Cakile maritima cannot be discounted from our results, it is not required to explain the levels of variation in the latter species observed in Australia. Cakile maritima continues to spread southwards in Tasmania and northwards in NSW; in Queenland, a recent occurrence has proliferated in Moreton Bay, spreading slowly to the north but not appreciably southwards.
\end{abstract}

Cunninghamia (2013) 13: 275-290

doi: 10.7751 cunninghamia.2013.005

\section{Introduction}

Two sea rockets (Cakile Mill., Brassicaceae) have spread around Australia's southern and eastern coastlines (Rodman 1986). They are mostly found close to the sea, typically, though not exclusively, at the top of the strand line and in the lower foredunes of sandy beaches. Cakile edentula (Bigelow) Hook., an annual self-fertilising species from eastern North America, has now probably completed its spread, whereas Cakile maritima Scop., an out-crosser from Europe and North Africa, is still spreading into areas previously occupied by Cakile edentula, replacing the latter species as it goes.
Although invasive species arrivals are usually sequential, this rare example of complete replacement of one invader by another is notable in that it has also occurred in southwestern North America (Barbour \& Rodman 1970) and New Zealand (Cousens \& Cousens 2011).

Despite their local abundance, the species are seldom controlled by managers as their impacts are perceived as slight. Although they form small incipient dunes, their impact on larger scale coastal geomorphology is probably insignificant; they compete with few native plant species (southern Australia has a very limited native strand flora); they have both negative and positive impacts on native and 
exotic birds and insects, but these have never been quantified; and although they are obvious to beach-goers, they do not significantly impact on their enjoyment (Cousens et al. 2013).

The invasions of Cakile in Australia have been described previously by Rodman (1986), but their spread has been rapid and further changes in their distributions have occurred in the last quarter of a century. The advent of databases has also meant that further records important in the invasion chronology, but unavailable to Rodman, have come to light. Significantly, there remains considerable confusion amongst ecologists about the identification of the taxa in Australia. Specimens are frequently incorrectly identified and thus the progress of the invasions cannot be charted by simply consulting databases such as Australia's Virtual Herbarium, databases of State Government departments or local species lists. Adding to the confusion, it has been claimed that the high level of morphological variation in Australian Cakile maritima compared to North America (where it is also exotic) has arisen from hybridisation and introgression from Cakile edentula in this country (Cody \& Cody 2004); statements have also been made on web sites that hybrids are common and often predominate (Queensland Government 2012). The alternative explanation of the morphological variation, multiple introductions from the native range, has not been considered. Repeated introductions may have given rise to regional variation in the species as well as to variability within some regions.

The aim of this study was to better document the invasion history of the species in Australia by: (a) confirming the identity of available herbarium specimens in all major Australian herbaria, through reference to variation in the species within their native ranges; (b) using the resulting confirmed herbarium databases to establish times of introduction to, and disappearance from, different regions of the country; (c) surveying areas believed to be at the leading edges of the Cakile maritima invasion, thus establishing the current extent of the invasion; and (d) examining morphological variation within and between sites across the country to see whether this provides additional clues.

\section{Methods}

\section{The species}

Before describing the research methods, we briefly review the taxonomy and distribution of the two species overseas. This will help to explain the measurements that we have made and aid in their interpretation. Both species have fruits divided into two single-seeded sections (though either the proximal or both proximal and distal may not develop); the distal section disarticulates readily as it ripens while the proximal remains on the maternal parent. As well as the transverse abscission zone between the proximal and distal fruit segments, an abscission zone can be seen running from top to bottom around the fruit (the replum) along which each segment later splits to release its seed or when the seedling emerges. Henceforth, for ease of discussion, it is assumed that this replum is lateral when examining a fruit. The two species and their subspecies can be distinguished most readily by fruit and leaf characters and this is used in most keys. The species also differ in various aspects of flower morphology (Rodman 1974). For example, Cakile edentula mean petal width is only half that of Cakile maritima (Rodman 1974; Cody \& Cody 2004). Although most Australian State and national floras give ranges of petal length for the species that would appear to be of diagnostic value, petal lengths of the two species recorded in their native distributions overlap to some extent (Rodman 1974; Tutin et al. 1993; Rich 1992), as do the lengths of the lamina of the open flowers (the petal's "limb" - Rich 1992) in North America (Cody \& Cody 2004). Our own unpublished measurements in Australia also suggest that petal lengths are of minor taxonomic use.

Two subspecies of Cakile edentula are usually recognised in its native range: harperi (Small) Rodman and edentula (Rodman 1974) [though Cakile arctica Pobed. is sometimes referred to as Cakile edentula subsp. islandica (Tutin et al. 1993)]. Subspecies edentula has two varieties, edentula and lacustris Fernald. Australian material has previously been ascribed to Cakile edentula subsp. edentula var. edentula, which has a native distribution from Labrador to North Carolina. There is a distinct narrow waist between the two fruit segments in this subspecies (Fig 1a). The lower segment is circular in transverse section and is somewhat narrowed at both ends, forming an elongated barrel shape. The upper segment is globular, with an elongated "beak" that is commonly dorsiventrally flattened and the apex is often emarginate and a dark red/purple. Where the proximal and distal fruit segments separate, the abscission scar is virtually flat or with a few slight projections, but never saddle-like (as in Cakile maritima). The leaves are usually coarsely serrate to incised (Fig 2); however, those formed early or late in plant development may merely have a few marginal notches.

Cakile maritima is highly variable in its native range. The presence of lateral "horns" or "spurs" on the proximal fruit segment (Fig. 1b) is considered diagnostic for the species (Rodman 1974; Hewson 1982), but these projections vary in size and form geographically and within populations: Ball (1964) comments that the spurs are "small, often absent" along the Atlantic coast of Europe (Fig 1g) to over $1 \mathrm{~mm}$ long in the Mediterranean (Fig. 1h) and Baltic (see also Castroviejo 1996). There are clear geographic trends in fruit morphology that appear to undergo rapid transitions in parts of the range (supported by molecular studies: Clausing et al. 2000; Kadereit et al. 2005), but the places to draw the lines (both geographically and morphologically) and how many lines to draw are still open to debate. Leaf margins in the species also vary from entire to coarsely serrate to pinnatisect to almost bipinnatisect (Fig. 3) according to geography (Davy et al. 2006; Rodman 1974; Tutin et al. 1993), but they also vary within a region or site (Ross-Craig 1958, Gandour et al. 2008, Mouterde 1970, Ciccarelli 2010).

Infra-specific taxonomy in Cakile maritima is based primarily on fruit and leaf shapes (Pobedimova 1963; Ball 1964; Rodman 1974), but descriptions of the subspecies 
recognise the existence of considerable overlap in both traits. The current convention in Europe (Marhold 2011, which we use in this paper) recognises four regional subspecies: subsp. maritima in the Mediterranean; subsp baltica (Rouy \& Foucaud) P.W. Ball in the Baltic; subsp. integrifolia (Hornem.) Greuter \& Burdet on the Atlantic coasts; and subsp. euxina (Pobed.) Nyárády in the Black Sea [but note that, confusingly, in Flora Europaea (Tutin et al. 1993) subsp. maritima is the Atlantic subspecies and subsp. aegyptiaca is the Mediterranean subspecies]. Fruits can apparently be distinguished on the basis of the shape of the proximal fruit segment viewed side-on after the distal segment has disarticulated and by the length of the spurs (Ball 1964). Leaf shape diagnostics are more confused. While plants of subsp. maritima are most commonly pinnatisect, some plants have entire margins (Gandour et al. 2008, Ciccarelli 2010, and have been referred to as var. latifolia (Mouterde 1970) or var. integrifolia on various herbarium specimens: R.D. Cousens, unpublished), and others are bipinnatisect (Davy et al. 2006 and our own observations) - even though Flora Europaea (Tutin et al. 1993) confines bipinnatisect leaves to subsp. euxina and baltica. Despite its name, leaves of subsp. integrifolia may have entire or serrated margins, or may be deeply lobed (Ross-Craig 1958).
In addition to Australia, Cakile edentula has spread to the Pacific coast of North America, New Zealand (including the Chatham Islands), Japan and the Azores (floras published in the invaded ranges rarely identify the Cakile subspecies); var. edentula has spread from the Atlantic into the Great Lakes. Cakile maritima has colonised Australia, New Zealand (including the Kermadec Islands), New Caledonia, the Caspian coast of Iran, eastern South America and the Pacific coast of North America; it has been recorded in a few locations on the east coast of the USA. Herbarium specimens in Australia may often be labelled subsp. maritima or subsp. baltica (apparently following Rodman's recognition of three subspecies, where subsp. maritima extends from the North Atlantic to the Mediterranean).

\section{Confirmation of specimen identification}

We accessed all available specimens in the major Australian herbaria (AD, BRI, CANB, HO, MEL, NSW, PERTH) (herbarium codes follow http://www.sweetgum.nybg.org/ ih/) except the Australian Tropical Herbarium (CNS) and the Northern Territory Herbarium (DNA) as Cakile does not occur in tropical Australia. Many specimens had only fruits, some had no flowers and others no leaves. Where present, we
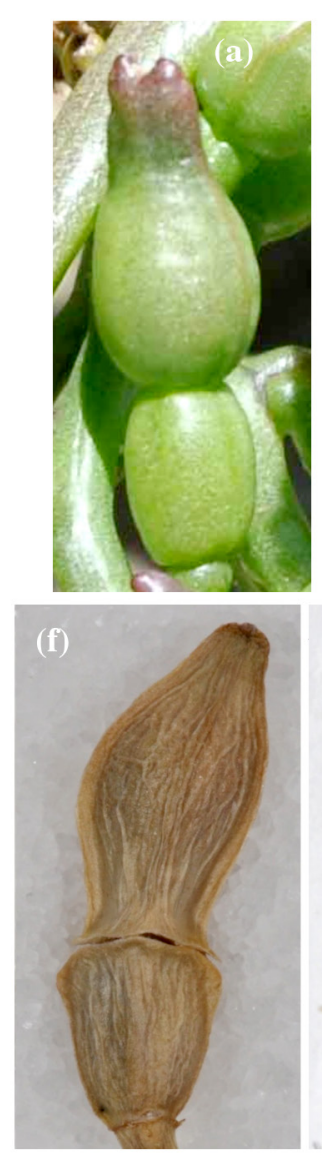
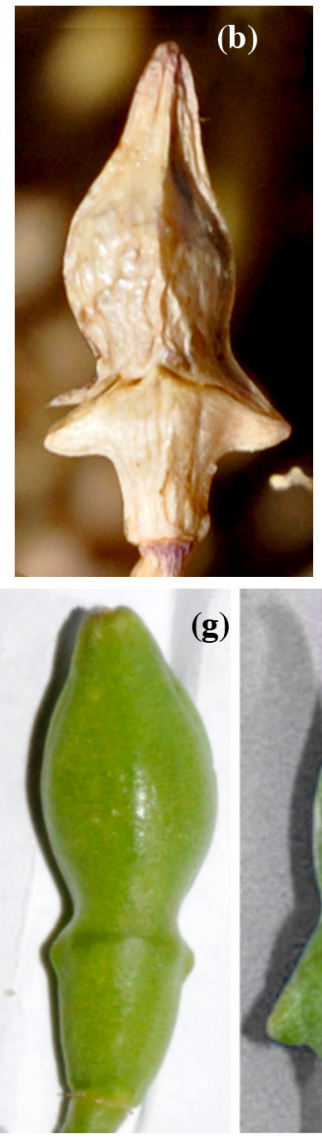

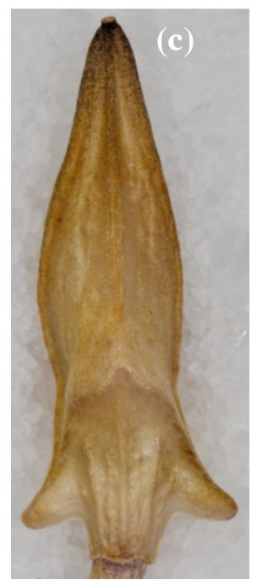

(h)

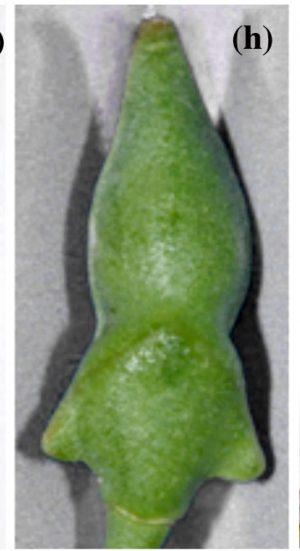

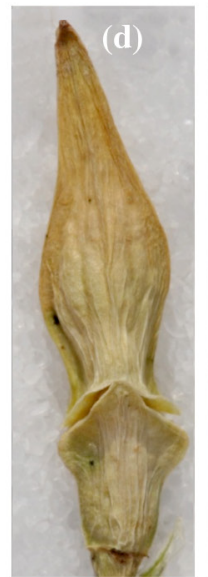

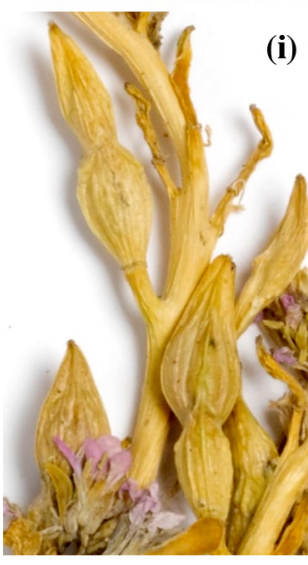

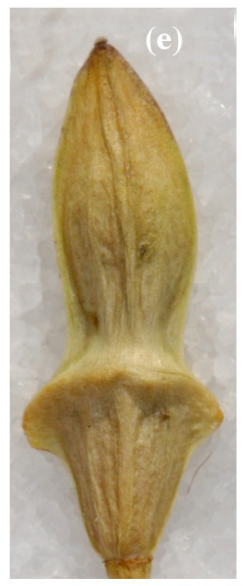

(i)

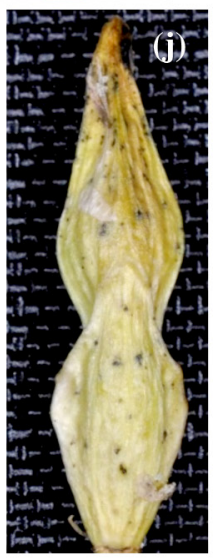

Fig. 1. Fruit shape variation in Cakile: (a) Cakile edentula subsp. edentula from Bolton's Beach, Tasmania, (b) Cakile maritima from Sulphur Creek, Tasmania, (c,d) Cakile maritima from West Lakes Shore, South Australia, (e) Cakile maritima from Applecross, Western Australia, (f) Cakile maritima from Golden Bay, Western Australia, (g) Cakile maritima subsp. integrifolia from Cantabria, northern Spain, (h) Cakile maritima subsp. maritima from Torremolinos, southern Spain, (i,j) putative hybrids from Sloping Main, Tasmania (Cousens n.c., HO565167). Specimens of Australian Cakile maritima were chosen to represent the range of variation in Australia rather than to be typical of each site. Photographs are taken such that the replum runs round the circumference. 

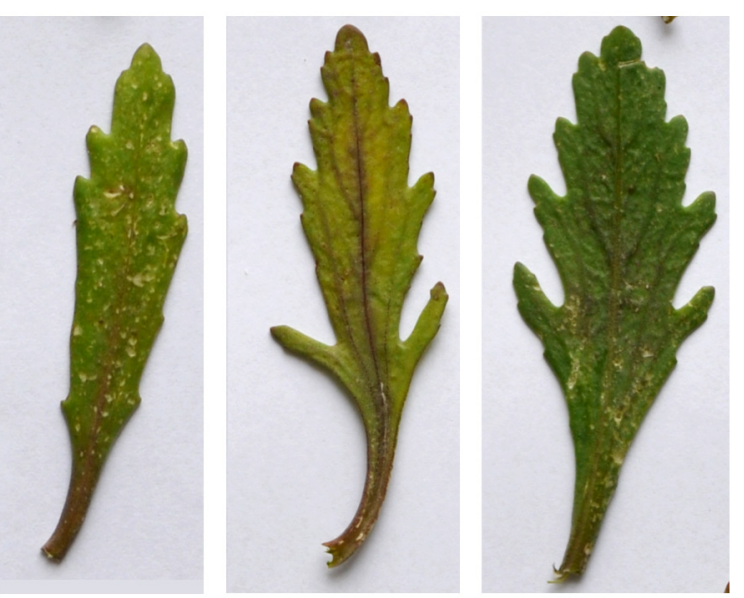

Fig. 2. Examples of leaf shapes of Cakile edentula from Tasmania.

examined fruit shapes, paying particular attention to shapes of both fruit segments and the abscission scar left after the distal fruit had separated. Floral features were examined in detail only where identification was difficult to ascertain from fruit and leaf shapes.

Reference material describing the species was obtained from a wide range of sources. The herbarium collection at KEW was examined, covering most of the native range of Cakile maritima and parts of the native range of Cakile edentula. Key publications consulted about infraspecific variation included Ball (1964), Rodman (1974) and Davy et al. (2006). Additional taxonomic information on Cakile maritima was obtained from Tutin et al. (1993) and Euro+Med Plantbase (Marhold 2011), as well as through personal communication with James Rodman. We also consulted a wide range of regional pictorial floras and scientific papers depicting morphological variation within the native ranges (e.g. Gandour et al. 2008; Ciccarelli et al. 2010). Finally, we surveyed photographic images and line drawings obtained through Google ${ }^{\mathrm{TM}}$ searches.

\section{Invasion history}

Having corrected the determinations of specimens where necessary, we examined the databases supplied by each herbarium. For each State, as well as for distinct geographic regions, we identified the first and last collections of each species. At PERTH and AD we accessed letters that were relevant to the invasion history and at $\mathrm{AD}$ we were provided with previously unlabelled specimens.

To determine current range limits more accurately, we surveyed beaches in regions encompassing the apparent areas of species overlap, in Tasmania in February 2012 and 2013 and in northern NSW/southern Queensland in October 2012. Beaches were chosen according to accessibility, previous herbarium records, previous surveys (P.C. Heyligers, unpublished data) and available time. At each beach, sufficient distance was walked until both species were recorded or until it seemed unlikely that a species was present (typically around $500 \mathrm{~m}$ ).

\section{Morphological variation within and between regions and populations}

Each of the 845 confirmed herbarium specimens of Cakile maritima was, where possible, assessed for leaf shape (using the scale in Fig. 3) and the shape of the proximal fruit segment when viewed at $90^{\circ}$ to the replum (Fig. 4). Our ordinal leaf shape scale differs somewhat from those of Cody \& Cody (2004) and Gandour et al. (2008) as some of their categories were difficult to distinguish and the correct order of their shapes is debatable. Since the shape of leaves changes during development, with young leaves and uppermost stem leaves being the least lobed, we scored the leaf on each plant having the highest value on the shape scale. Our fruit shape scales also differed from those authors, since ours is based on photographs of actual fruits. Fruits were only scored if they were fully grown and the proximal segment had developed; where there was variation among fruits, we scored the one
1

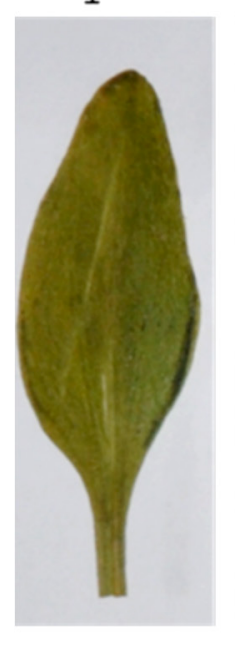

2

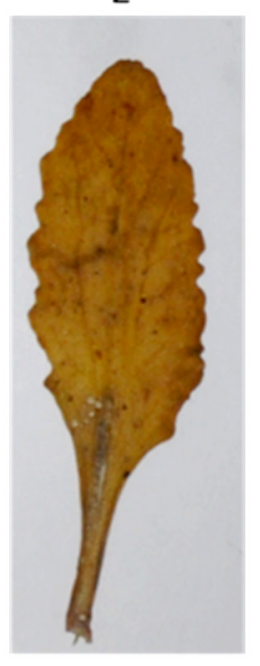

3

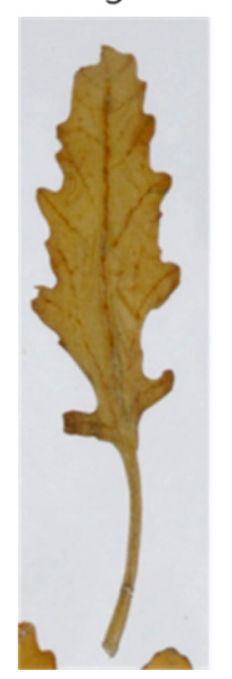

4

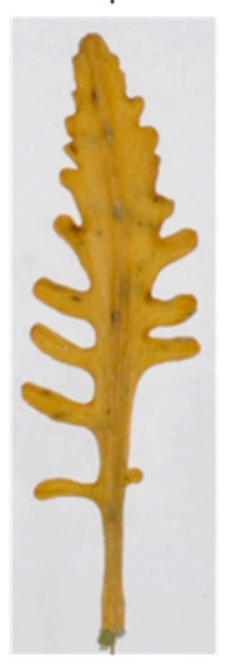

5

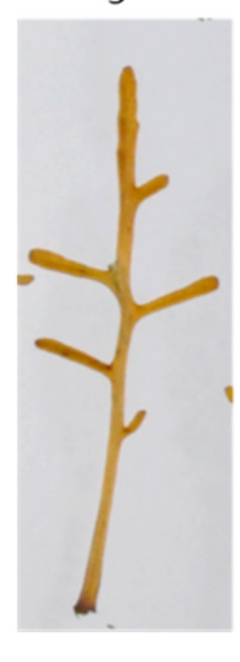

6

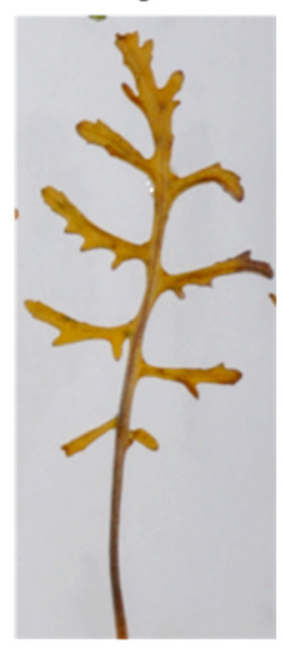

Fig. 3. Range of leaf shapes of Cakile maritima in Australia. Numbers indicate classes used in morphological analysis. 
1

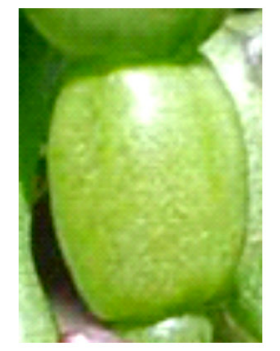

2

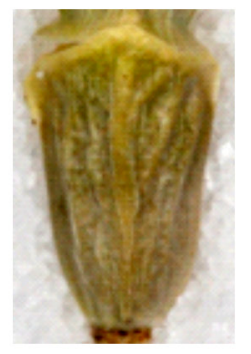

3

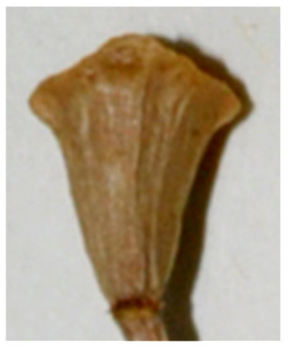

4

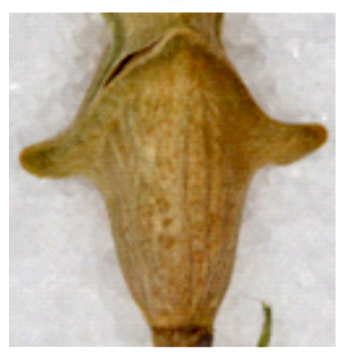

5

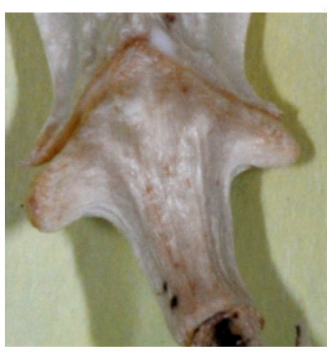

Fig. 4. Range of shapes of proximal fruit segment found in Australian Cakile. Left (1) is typical of Cakile edentula; others (2-5) are Cakile maritima.

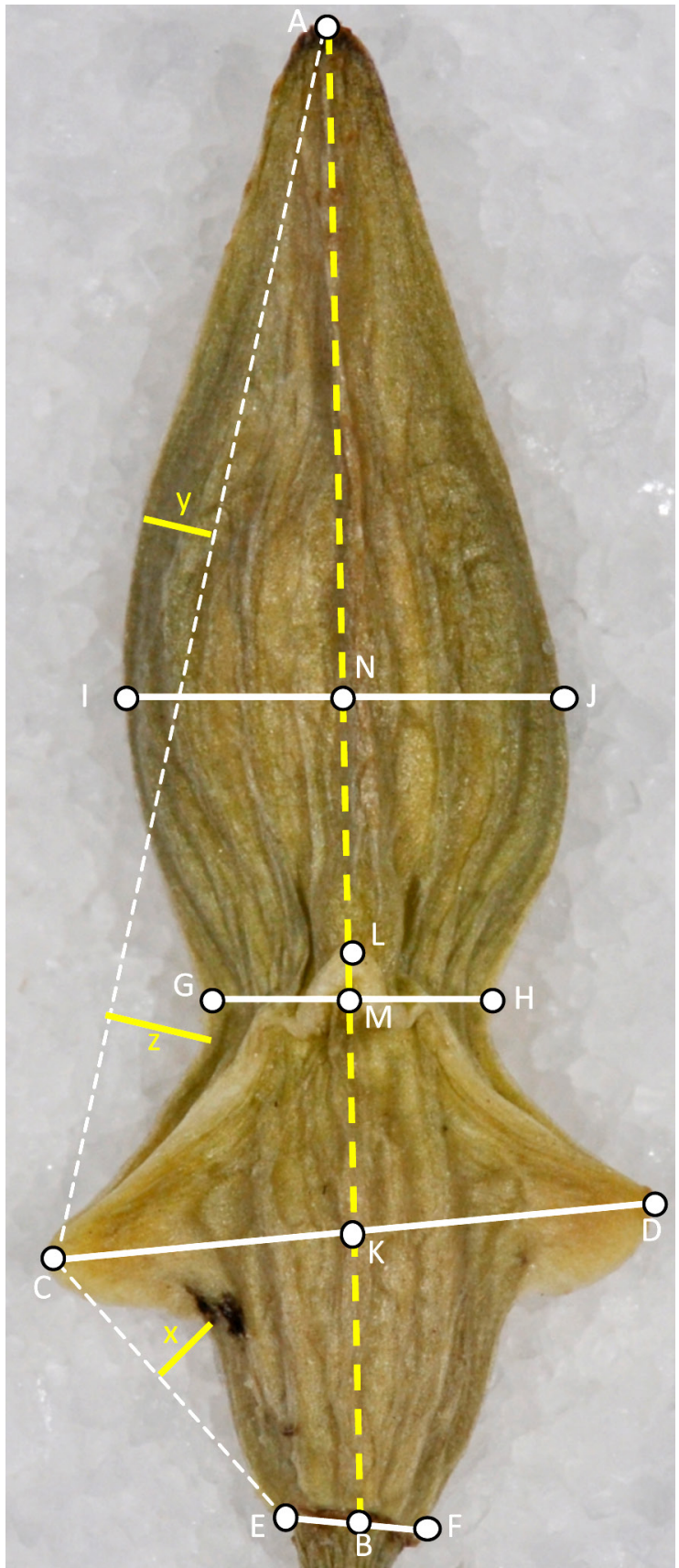

Fig. 5. Cakile maritima fruit, showing 'landmarks' and distances recorded in morphometric study. with the highest value on the shape scale. Relative frequency distributions of leaf and fruit attributes were constructed on a State basis; collections of Cakile maritima from Queensland were included with NSW due to small sample size.

We also collected samples of leaves and fruits from fifty plants at each of three sites in Western Australia (Applecross, Golden Bay and Woodman's Point), one site in each of South Australia (West Lakes Shore, also sampled by Cody \& Cody 2004), Victoria (Lakes Entrance) and Lord Howe Island (Lagoon Beach), and two sites in Tasmania (Marion Bay and Burnie) (Table 1). At each site, the nearest plant was sampled at $5 \mathrm{~m}$ intervals along the shore. A single ripe, intact fruit with a developed proximal fruit section and the leaf with the greatest degree of lobing were collected. Leaves were scored using Figure 3. Fifty plants were also scored for leaf shape at Beachmere, north of Brisbane, Queensland. Fruits were air-dried, then photographed at $90^{\circ}$ to the replum. Attributes of all fruits were measured on the digital images of 19 random fruits using tpsDig Version 2.16 (Stony Brook Morphometrics, USA). Traits measured were CD, EF, GH, IJ, KB, LB, MB, NB, x, y, and z (Fig. $5)$; these were all standardised by dividing by total fruit length $(\mathrm{AB})$. Four derived variables were also calculated: $\mathrm{CD} / \mathrm{LB}, \mathrm{CD} / \mathrm{EF}, \mathrm{x} / \mathrm{CD}$ and $(\mathrm{LB}-\mathrm{KB}) / \mathrm{CD}$. We attempted to obtain fruit measurements from herbarium specimens from the native range (representing Cakile maritima subsp. maritima, baltica and integrifolia), but fruits were rarely mature, intact and lying in the appropriate plane. The opportunity arose to obtain photographs of a small number of fresh fruits from single sites on the Atlantic (14 fruits) and Mediterranean coasts of Spain (four fruits) representing part of the variation within Cakile m. integrifolia and Cakile $m$. maritima respectively). The most fully developed, intact fruit was collected from every mature plant on the beach, but these were photographed fresh rather than dried (and thus potentially affecting morphometric measurements).

Frequency distributions of leaf and proximal fruit segment shapes were analysed using generalized linear models (multinomial distribution with cumulative logit link in SAS); chi-square tests were used to compare States or locations. Morphometric data were analysed using Principal Components Analysis in SAS. 
Table 1. Locations of Cakile collections for morphometric analysis.

State
Western Australia
Western Australia
Western Australia
South Australia
Victoria
New South Wales
Tasmania
Tasmania

\section{Results}

\section{Confirmation of herbarium specimen identification}

The great majority of specimens fell within the range of variation documented for each of the two species in their native ranges. Thus, attribution to a species was mostly straightforward. We altered the determinations of a small number of specimens in most herbaria, usually from Cakile edentula to Cakile maritima.

Our observations supported the classification of Australian Cakile edentula as subsp. edentula, notably with respect to the constriction between the proximal and distal fruit segments. Within Australian specimens of Cakile maritima, we found the complete range of leaf shapes exhibited by plants within the native range of the species (see also Heyligers 1989; Davy et al. 2004); the same was true for proximal fruit segments, which ranged from hastate with wide "horns" to having almost no horns at all. It was usually impossible to ascribe a particular specimen to a subspecies using the guide published by Ball (1964) or the photographs in Rodman (1974): a proportion of specimens had the strongly deflexed horns depicted for subsp. maritima (Ball's aegyptiaca), but most horns were not deflexed and were of intermediate size and thus could correspond to several of Ball's drawings. Few specimens had a flat top to the abscission scar (when viewed along the plane of the replum), as depicted by Ball for his Baltic and Atlantic subspecies, but the shape was also seldom the smooth convex curve shown for the other subspecies. Thus we were unable to confirm the identification of specimens in herbaria labelled Cakile maritima subsp. baltica (or indeed most labelled Cakile maritima subsp. maritima).

Just a few specimens were difficult to allocate confidently to either species. Some of these had fruit characters suggesting that they were intermediates. The overlap in leaf shapes of the two species and the great range in Cakile maritima fruit morphology means that the identification of hybrids must be extremely uncertain. We identified just 13 possible hybrids, but several of these lacked many distal fruit segments and leaves. Specimens collected from regions and periods in which the species were sympatric, and with unusual shaped fruits, include Cleland s.n. (AD966040594), Gray 6652 (CANB349172, 349173), Heyligers 79163,
Latitude (S)

$32^{\circ} 0.7$

$32^{\circ} 25.9^{\prime}$

$32^{\circ} 7.5^{\prime}$

$34^{\circ} 52.3^{\prime}$

$37^{\circ} 52.8^{\prime}$

$31^{\circ} 31.8^{\prime}$

$42^{\circ} 50.2^{\prime}$

$41^{\circ} 2.9^{\prime}$

\section{Longitude (E)}

$115^{\circ} 49.8^{\prime}$

$115^{\circ} 45.0^{\prime}$

$115^{\circ} 45.5^{\prime}$

$138^{\circ} 28.8^{\prime}$

$148^{\circ} 0.4^{\prime}$

$159^{\circ} 4.0^{\prime}$

$147^{\circ} 52.6^{\prime}$ $145^{\circ} 54.1$
79192 (CANB291551, 291552, 291326), Melville 2231 (NSW642911), Cousens s.n. (HO565167; Fig. 1i,j).

\section{Invasion history}

The arrival and spread of Cakile edentula. There are early records of Cakile edentula in southern Australia from the 1860 s and 1870 s, and although it is tempting to deduce that the first record represents the first region of entry and that the species subsequently spread from there (Rodman 1986; Sauer 1988) such a chronology is by no means certain since collection intensity at the time was very low. Cakile edentula was first collected on Phillip Island, Victoria by F. Mueller in 1863 (s.n., MEL1004009): he noted "known there wild since 20 years". The first New South Wales specimen is from Manly Beach in 1870 (Woolls s.n., MEL1004032), while the first record from Tasmania was on the north coast near Circular Head (Stanley) in 1875 (Mueller s.n., MEL1004023). It was in South Australia by 1881 (Destrees Bay, Kangaroo Island: Tate s.n., AD97324157).

There is some doubt about the eventual limit of Cakile edentula's westwards spread. It had established at The Head of the Bight by 1955 (Cleland s.n., AD97229257) and near Eucla by 1962 (Phillips s.n., NSW131654). A sample from Esperance Bay in 1952 (Carpenter s.n., PERTH 3236900) lacking distal fruit segments appears also to be Cakile edentula but a sample collected from Mandurah, south of Perth, in 1970 by H. Salasoo (4052, NSW120069, cited by Rodman 1986) was incorrectly identified. Therefore, although Cakile edentula spread along the Bight, there is no evidence that it has ever occurred further west than Esperance.

On the east coast, Cakile edentula spread northwards, though a paucity of samples from NSW makes its chronology uncertain. It was in Queensland by 1922 (Stradbroke Island: White 1680, BRI278332) and had reached Heron Island by 1958 (Gillham s.n., BRI278327). The most northerly records are Mackay (1993: Champion 878, BRI621568) and Bushy Island (1989: Walker s.n., BRI457562). Surveys further north are needed to confirm the limits of distribution (the small, highly ephemeral populations - Heyligers 2007 - make surveys difficult). Cakile edentula was present on Lord Howe Island by 1898 (Pickard, 1984; King s.n., NSW104038;). In Tasmania, Cakile edentula was at Port Davey on the west coast by 1893 and Hobart by 1900 . 


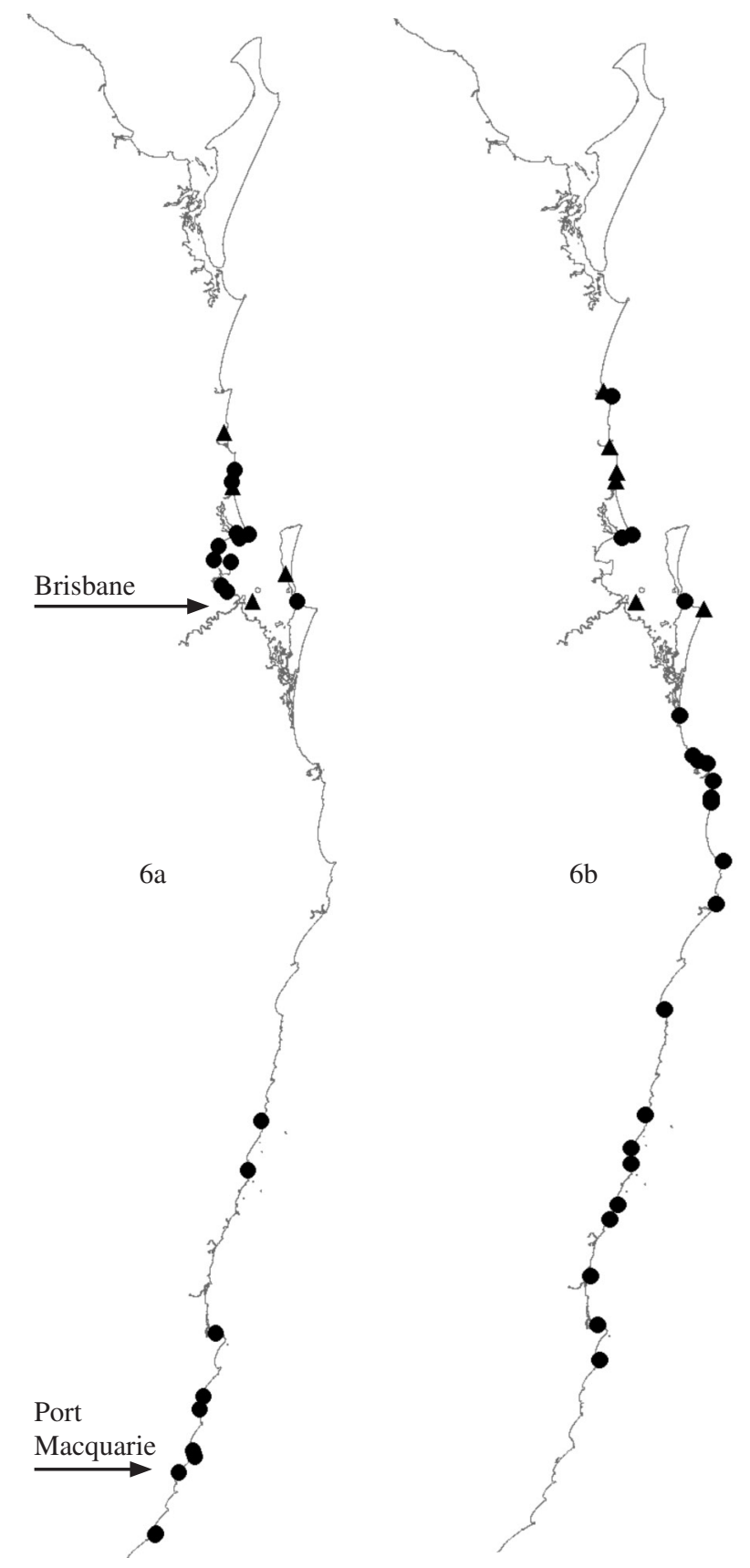

Fig. 6. Presence data (solid circles) from survey of northern NSW and southern Queensland in November 2012. (a) Cakile maritima, (b) Cakile edentula. Triangles are herbarium records and unpublished observations by PC Heyligers, both since 2000 .

The arrival and spread of Cakile maritima. Cakile maritima first appeared in Western Australia (Fremantle, 1897: Helms s.n., PERTH3236757). It had reached Albany on the south coast by 1901 (Goadby 142, PERTH3236749). The first collections from the eastern States were from South Australia in 1918, from the coast (Adelaide, unnamed AD254851) and from about $100 \mathrm{~km}$ inland (Kybybolite, Andrew s.n., AD97227097). Although it is possible that the latter may be a labelling error (P.C. Heyligers, pers. comm.), there is correspondence (but no other specimens) in the State Herbarium of South Australia concerning Cakile in that region: a weed adviser from the Department of Agriculture writing in 1949 states that a sample from a sandy ridge in a field near Pinnaroo had been identified as Cakile maritima. There is also a more recent inland collection, from Broken Hill (1977: RJS 2045, NSW642909) on an old zinc mine spoil heap.

Cakile maritima was first collected in Victoria at Beaumaris, a Melbourne suburb, in 1922 (Tadgell s.n., MEL1003990). It was not recorded until 1968 in NSW, at Nadgee River in the south, but collections soon after that (e.g. Woy Woy 1969: McBarron 17663, NSW642907) suggest that it may already have been widespread in southern NSW by that time. The species was first collected on Lord Howe Island in 1992 (Swarbrick 10492, BRI589916). Heyligers (pers. comm.) found Cakile maritima as far north as Port Macquarie in 1998, while in our survey in November 2012 (Fig. 6) the most northerly site we located for Cakile maritima was Wooli Beach (about $180 \mathrm{~km}$ further north; note that this beach was also visited in Heyligers' survey but found to have only Cakile edentula). In 2002, Cakile maritima was found in southern Queensland (Bribie Island: Heyligers s.n., BRI558626, 558627) and has since been collected from several beaches in that region, as far north as Coolum. In 2012, all mainland sandy beaches in the Moreton Bay area contained Cakile maritima; in 2011 both species were present on North Stradbroke Island. Although Cakile maritima was also common at Golden Beach, Caloundra in 2012, it was only found at one site further north (Currimundi Lake, south of Coolum) in that survey. Although it seems plausible that the mid-NSW invasion front leapfrogged the northern NSW coast to arrive in Moreton Bay, we note that there are morphological differences between populations in NSW and Queensland. Those in Moreton Bay almost (but not quite) exclusively have pinnatisect leaves (leaf type 5, Fig. 3) and always have distinct horns on the fruits (also noted previously by Heyligers); the majority of plants in mid-NSW had serrate or slightly lobed leaves (leaf types 2-4, Fig. 3) and the fruits have a range of horn lengths.

In the Bass Strait, Cakile maritima was collected from Deal Island in 1957, Flinders Island in 1972 and King Island in 1979. The first record for mainland Tasmania is Sullivan's Cove, Hobart in 1963 (Pearson 581, MEL577437), although it does not appear to have persisted in that part of the State. The first record in northern Tasmania was 1979 and on the east coast was 1987. An extensive survey of western Tasmanian beaches in the mid-1980s found Cakile maritima on most beaches (along with Cakile edentula) (Fig. 7c). By February 2012, Cakile maritima was as far south as the east coast of Bruny Island (Fig. 7a), with only beaches around the Derwent River and D'Entrecasteaux Channel yet to be invaded.

\section{The demise of Cakile edentula.}

The last Cakile edentula collection known from South Australia was in 1983 (in the Bight: Toelken 7635, AD98415058). It appears to have persisted longer in the Bight (at least 75 years after Cakile maritima was first recorded in South Australia) than further east in the State (where the last Cakile edentula specimens were collected 
in 1936). The first Cakile edentula specimen collected in the Bight (here defined as between Eyre, Western Australia and Fowler's Bay, South Australia) was 1955 (Cleland s.n., AD97229257) and the last 1983; the first Cakile maritima collection from that region dates from 1984 (Downing 1006, PERTH3279979) and all Cakile specimens from that date onwards have been of this species. A more systematic field survey might show that Cakile edentula still exists in this remote region. Possible hybrids have been reported from the eastern side of the Bight in 1979 (Heyligers 79163, 79192, CANB291551, 291552, 291326).

The most recent collection of Cakile edentula from Victoria dates from 1986, from the far east of the State (Thurra River: Heyligers 86035, CANB403745) (P.C. Heyligers, pers. comm., also reports it nearby at Wingan in 2000). The most recent specimen from Victoria west of Melbourne dates from 1953 (Melville 3191, MEL520919). In the mid-1980s both species could be found together in southern NSW (Heyligers, 1984), but this no longer appears to be the case. The southern limit of Cakile edentula in the late 1990s was Forster (P.C. Heyligers, unpublished data), while the two species were sympatric on several beaches between there and Port Macquarie (a range overlap of about $100 \mathrm{~km}$ ). In November 2012, the most southerly Cakile edentula found was at Hat Head (Fig. 6), $160 \mathrm{~km}$ north of Forster (i.e. an estimated range contraction of $12 \mathrm{~km}$ per year), with a sympatric zone of perhaps $120 \mathrm{~km}$. It should be noted that within the sympatric zone, some beaches only had Cakile edentula present and the furthest northwards "satellite" populations of Cakile maritima were a long way apart. Off the NSW coast, all collections of Cakile on Lord Howe Island were Cakile edentula until 1978; all collections since 1992 have been Cakile maritima and in a detailed survey in November 2011 we failed to locate any remaining Cakile edentula.

In Queensland, Cakile maritima has spread to the north of Moreton Bay (though it is still uncommon north of Golden Beach, Caloundra), but apparently not to the south. Within Moreton Bay, most beaches (including those at which Cakile edentula has been collected in the past) in November 2012 contained only Cakile maritima, while on the western side of Bribie Island Cakile edentula is now very much less abundant

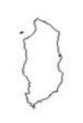

$7 \mathrm{a}$
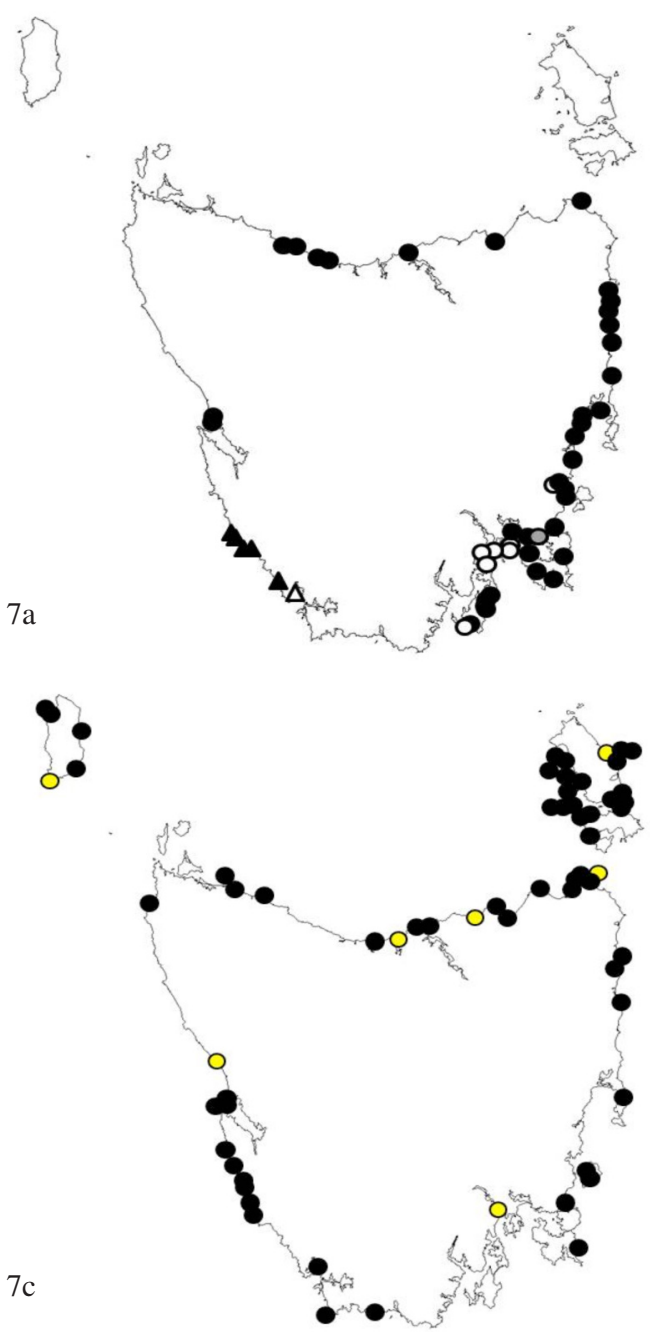
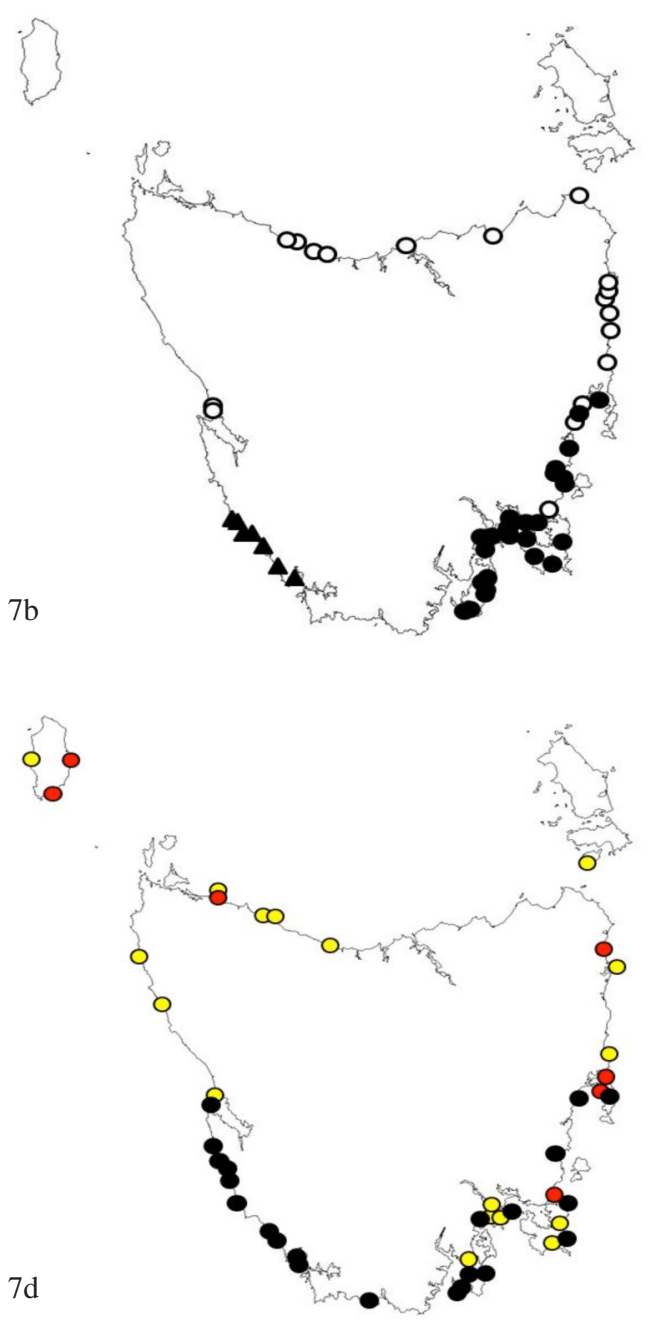

Fig. 7. (a) Cakile maritima, (b) Cakile edentula distribution data from survey of Tasmania in February 2012 (solid circles); (c) Cakile maritima, (d) Cakile edentula specimens in herbaria. Unfilled symbols in (a) and (b) indicate beaches sampled where Cakile was present but that species was not found; grey circle indicates possible presence (poor specimens with neither flowers or fruits); triangles are based on photographs by J. Marsden-Smedley. In (c) and (d) yellow circles are pre-1982; red circles indicate unpublished 1993 records of PC Heyligers. 
than Cakile maritima (the reverse of the situation reported by Heyligers in 2002/3).

In Tasmania, Cakile edentula now seems to have disappeared from all but the south-east corner of the State and the west coast. The most recent Cakile edentula herbarium specimen from the north coast of Tasmania dates from 1949, although P. C. Heyligers (pers. comm.) recorded a few plants near Stanley and two plants on King Island in 1993. On the east coast of the State, the species was still found as far north as St Helens in 1993 (P.C. Heyligers, pers. comm.), although the most recent herbarium specimen north of the Freycinet Peninsula was Bicheno in 1981. In a survey in February 2012 (Fig. 7), we were unable to find Cakile edentula except from the Freycinet Peninsula southwards. The two species were sympatric on most beaches from there southwards to the east coast of Bruny Island; a few likely hybrids were found at Raspin's Beach, Orford and at Sloping Main (Tasman Peninsula) but at all other beaches the species were usually easily distinguished. Only Cakile edentula was found on the west side of the South Arm Peninsula and at Cloudy Bay, Bruny Island in 2012. However, we found one Cakile maritima and two possible hybrids at Cloudy Bay in 2013, and several Cakile maritima and hybrids at Seven Mile Beach. In 2012, both species were still found on beaches in the south-west (J. Marsden-Smedley pers. comm. and photographs) although in most cases (but not all) Cakile maritima was more abundant. Thus probably only the area around the D'Entrecasteaux Channel and the Derwent River remain invaded only by Cakile edentula.

\section{Morphological variation within and between regions and populations}

All leaf types were present in herbarium collections from all regions (including Western Australia, where Cakile edentula has never been recorded west of Esperance). There were significant differences $(\mathrm{p}<0.0001)$ in the leaf shapes between regions (Fig. 8). South Australia and Western Australia had higher proportions of pinnatisect leaves (Type 5) than other States, while Western Australia had a distinctly greater proportion of bipinnatisect leaves (Type 6) than other States. Leaf type 4 was at a lower frequency than types 3 and 5 in all States. There were also significant differences $(\mathrm{p}<0.0001)$ in

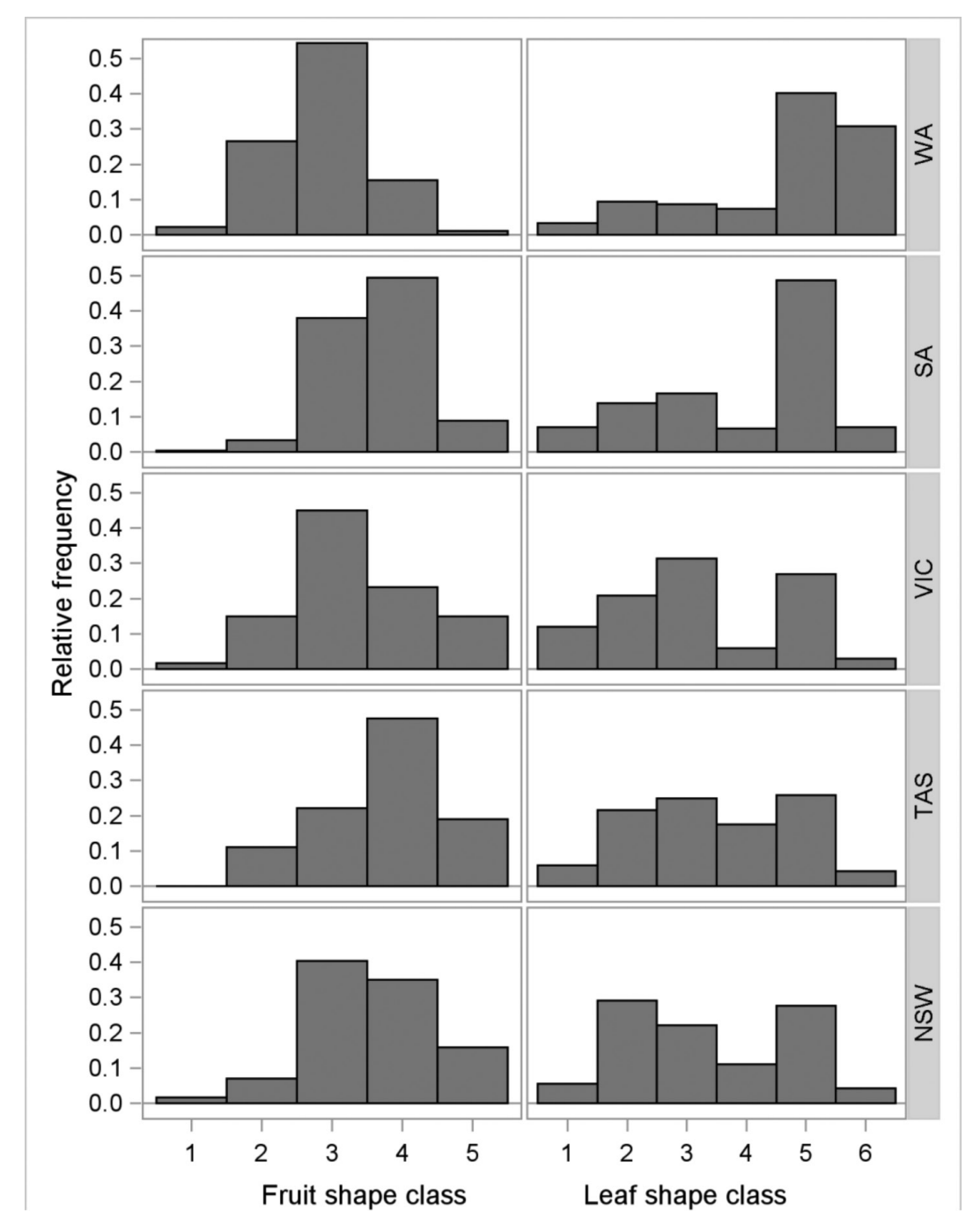

Fig. 8. Relative frequencies of shapes of Cakile maritima basal fruit segments and leaves represented within major Australian herbaria, according to the State in which samples were collected. See Figs. 3 and 4 for shape category scales. 
the frequencies of basal fruit segment shapes between States (Fig. 8). Shape 3, with only slightly developed horns, was least prevalent in Tasmania, while the greatest frequencies of shape 4 were in South Australia and Tasmania.

Leaf and fruit shapes in all the sampled populations were within the range of variation of Cakile maritima expected from its home range (including West Lakes Shore). There were significant differences in frequencies of leaf shapes between populations within a State $(\mathrm{p}<0.0001)$. For example, Tasmanian collections from Burnie and Marion Bay differed markedly, with the latter being dominated by unlobed or slightly lobed leaves (Fig. 9). Applecross (WA, beside the Swan River) plants were mostly pinnatisect and bipinnatisect, whereas populations at Woodman's Point and Golden Bay (on the open coast, $8 \mathrm{~km}$ and $40 \mathrm{~km}$ south of the river mouth respectively) had high proportions of crenate and entire leaves. It is interesting to compare this with the Western Australian herbarium data, mostly from ocean beaches, which were dominated by binnatisect and bipinnatisect leaves: either Woodman's Point and Golden Bay are atypical of populations in the State, or in recent years there has been an increase of unlobed leaf forms within the State. Lakes Entrance, Victoria, which has a similar leaf variation distribution to NSW in our experience, also differed in distribution from the population from Queensland.

The first three coordinates of the PCA explained $70 \%$ of the variation in fruit traits from the eight sampled sites. The first coordinate showed a strong tendency for Western Australian fruits to differ in shape from the other States (Fig. 10). Eigenvectors showed that the main traits influencing this east-west separation were related to standardised fruit length (Western Australian distal fruit segments tended not to be as long), distance of the horns from the base (Western Australian fruits tended to have short horns located further towards the distal end of the proximal fruit segment) and hastate shape of the proximal segment (eastern fruits tended to have a longer, more acute apex to this segment and more protruding lateral horns). Fruits from the Atlantic coast of Spain showed similar trait variation to Western Australia, whereas Mediterranean fruits were aligned with the eastern Australian samples.

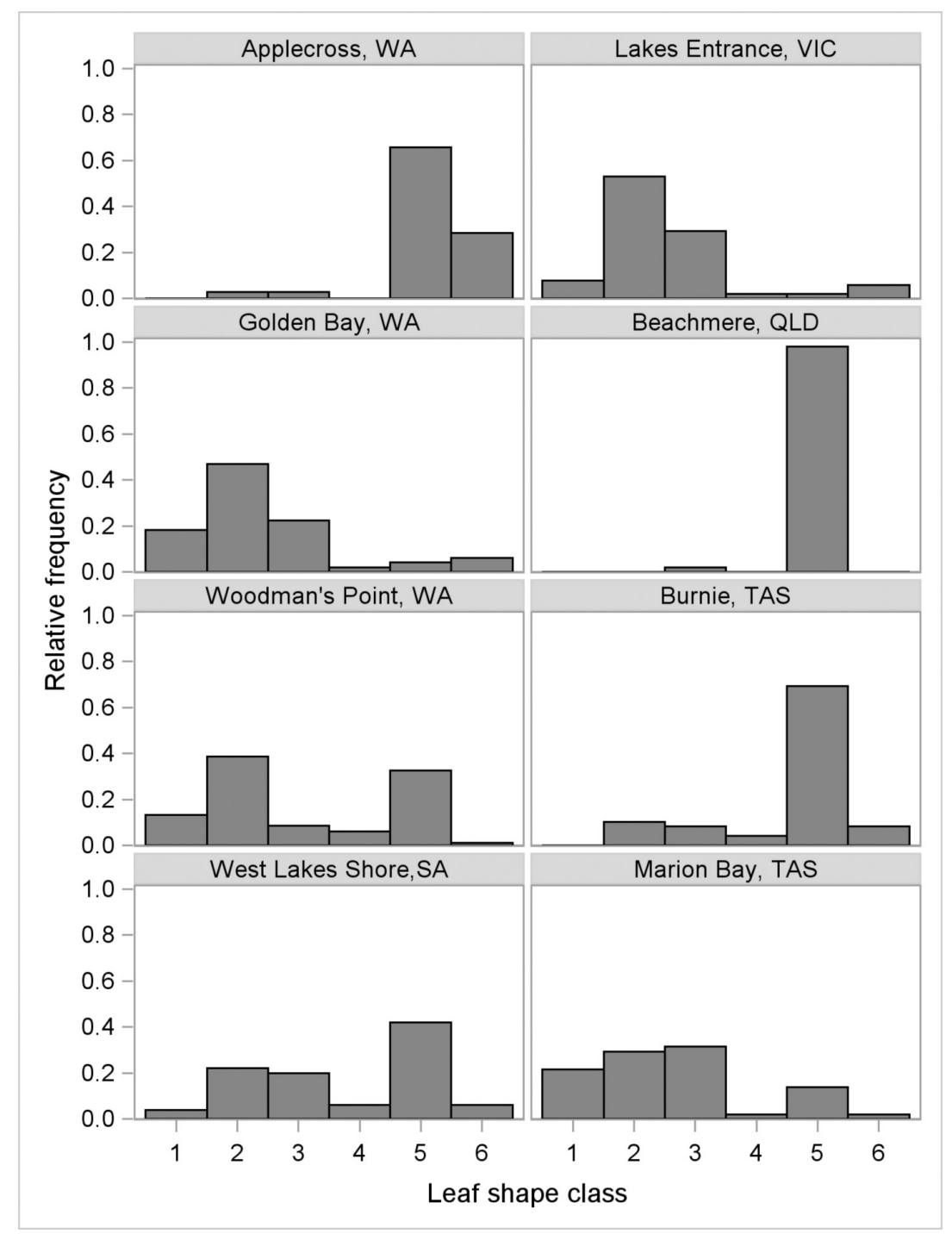

Fig. 9. Relative frequencies of leaf shape categories within populations of Cakile maritima from eight locations around Australia. 


\section{Discussion}

Much of the broad chronology of the Cakile invasions of Australia, set out in previous publications by Rodman (1986) and Heyligers (2007) based only on locations and dates of collections, is supported by our research. However, by considering morphological traits we suggest modifications of important aspects of the invasion history and question others. Our results also need to be considered in the light of another publication on the species in Australia that appeared after Rodman's study (Cody \& Cody 2004), in which a strong role for hybridisation/introgression was proposed. Our observations also have implications for the ways in which herbarium databases are being used by ecologists.

\section{Invasion history}

Previous interpretations of (largely) the same herbarium data have been based on the assumptions that (i) there has been a single introduction of each species, (ii) the invasion has been as a steadily moving wave (Sauer 1988), and (iii) the sequence of dates of the first herbarium collections in different regions reasonably reflects the invasion dynamics. There are reasons to doubt the accuracy of all these assumptions and hence the certainty of the conclusions.

(i) Our morphological evidence suggests strongly that there have been two or more introductions of Cakile maritima into Australia. The species did not simply sweep across the country from Western Australia, even though (a) that was the first place that it was recorded, (b) subsequent new collections followed a west to east sequence and (c) currents can carry floating objects rapidly from Western Australia into the Bight
(Heyligers 2007). Species often arrive in a new country on several occasions, as both morphological and molecular studies have shown (e.g. Okada et al. 2009). Multiple invasion opportunities are provided inadvertently and deliberately by commerce. If these introductions differ morphologically and they subsequently inter-breed in the new range, we would then expect a greater range of variation than in a single ecotype within the native range: hybridisation between species is thus not required as an explanation for high levels of variation (see below). It has been suggested that Cakile spp. were originally dispersed into Australia in the ballast of ships (Rodman 1986). Vessels such as those collecting grain docked at many smaller ports in southern Australia, not just the capital cities, providing numerous opportunities for new introductions.

The range of morphologies present in Cakile maritima in Australia is suggestive of at least two recognised ecotypes from its native range. This is supported by Rodman's (1976) studies of glucosinolate variation. A collection of his from Victoria contained glucosinolates similar to those from the western Mediterranean (i.e. Cakile maritima subsp. maritima, in which horns on fruits are pronounced), whereas a sample from South Australia shared affinities with both western Europe (i.e. Cakile maritima subsp. integrifolia, in which horns are often barely distinguishable) and the Mediterranean. Based on morphology, Rodman also suggested that some material was Cakile maritima subsp. baltica (his determinations, written on specimens in various herbaria); in particular, he suggested that Western Australian material might be this subspecies (letter to H.J. Hewson, 1976, copy in the Western Australian Herbarium). Our morphometric analyses show clearly that Western Australian populations of Cakile maritima differ from eastern Australian samples in fruit shape. This difference

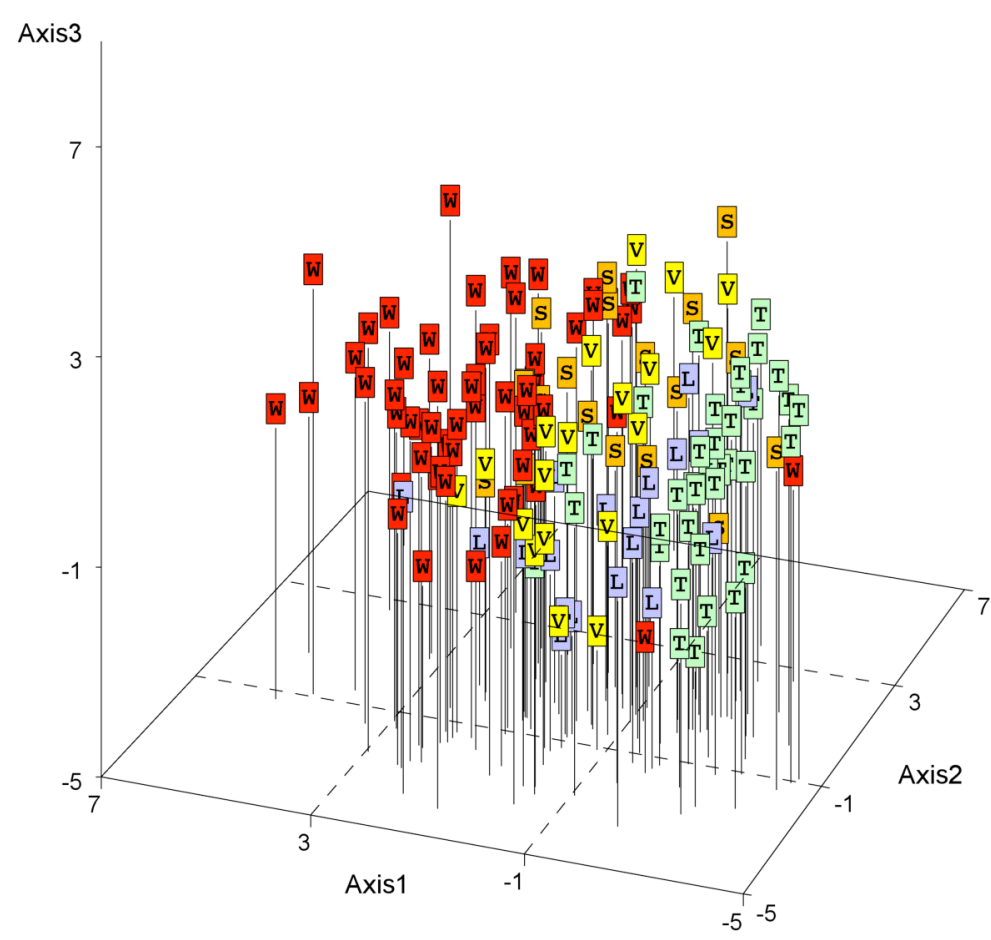

Fig. 10. PCA based on fruit traits of Cakile maritima. Letters refer to the region from which 19 plants were sampled from each of eight populations: Western Australia (W), South Australia (S), Victoria (V), Tasmania (T) and Lord Howe Island (L). 
between west and east is supported by molecular studies currently underway using microsatellites (Ohadi et al. 2012). We did not have access to material of Cakile maritima subsp. baltica, however, to test Rodman's subspecies determination. We included scores from Ball's (1964) fruit line drawings of three subspecies (including baltica) in our PCA, but they did not encompass the variation seen within Australia (all subspecies were towards the same corner of the PCA scatter, perhaps because the Ball's drawings are somewhat simplified). We note, however, striking similarities between fruits collected from northern Spain (i.e. Cakile maritima subsp. integrifolia) and fruits from Western Australia (Fig.1g vs 1f).

We could not determine whether there have been multiple introductions of Cakile edentula. Only a single subspecies appears to be present in Australia and there is little variation in both fruit and leaf morphology. No chemical analyses have been done on Australian material, though we are currently doing microsatellite comparisons of Tasmanian and NSW/ Queensland populations.

(ii) Most species do not spread as neat "waves" of plants moving steadily across the landscape. The furthest-dispersing seeds may have a low probability of survival and establishment (especially outbreeding species and where potential dispersal distances are long) and by chance only some beaches are colonised at first. Species thus make long distance jumps, initiating new satellite populations well away from the region already invaded ("invasion by extremes" - Clark et al. 2001). The gaps later fill in as the species spreads more locally (see Cousens et al. 2009). This pattern was seen in northern New South Wales, where the northern edge of the Cakile maritima invasion was very diffuse, with some beaches within the zone of overlap still having only Cakile edentula.

(iii) Intensity of collecting has been very uneven in space and time, particularly in the $19^{\text {th }}$ century, and has increased through time. Botanists often do not collect weeds and widespread invasive species (and these may not be a priority for herbaria). It would not be surprising if the first introductions to a region were overlooked for some considerable time, or if the first recorded location was a long way from the actual point of arrival. When Cakile edentula was first introduced there were few people collecting plants; travel was difficult and those collectors did not visit regions often. Then, as now, they did not necessarily make collections even if they saw them. For example, the first Australian collection of Cakile edentula (from Victoria) bears a comment that it had been noted from the region for about 20 years. The first Tasmanian collection of the species was by Mueller, who only appears to have visited beaches there on one of his three visits to the State (though others collected for him in Tasmania - R.W. Home pers. comm.). It is by no means certain that Cakile edentula was ever very abundant in Victoria and South Australia. We suggest, therefore, that the location of the first arrival of Cakile edentula in the south-east is very uncertain, even to the level of the State.

Another area in which the chronology is uncertain is The Great Australian Bight. This remote area is seldom collected thoroughly. The dates of first appearance of the two species and the disappearance of Cakile edentula (indeed, it may still occur there), based on herbarium collections, are likely to be very unreliable. However, it seems likely that it persisted longer there than elsewhere in South Australia and much of Victoria. A similar ongoing low collection frequency in Queensland, especially on the small islands of the Barrier Reef, make Cakile edentula arrival dates, as well as its current distribution, also uncertain.

\section{Rate of spread \& species replacement}

Despite the uncertainties due to low sampling effort and the possibility of multiple introductions, it has been tempting to estimate the rate at which the species have spread. Estimates from the Pacific Coast of North America based on herbarium collections are $64 \mathrm{~km} \mathrm{yr}^{-1}$ for Cakile edentula and $53 \mathrm{~km} \mathrm{yr}^{-1}$ for Cakile maritima (Barbour \& Rodman 1970). For Australia, Rodman (1986) estimated rates for the two species of $48 \mathrm{~km}$ $\mathrm{yr}^{-1}$ and $95 \mathrm{~km} \mathrm{yr}^{-1}$ respectively, commenting on the high latter value. However, if we discount the spread of Cakile maritima from Western Australia to South Australia, a figure of less than half is obtained (around $40 \mathrm{~km} \mathrm{yr}^{-1}$ ), more in line with other estimates. Comparison of our NSW/Queensland survey in 2012 with Heyligers' in 1998/9, taking the most northern NSW location in each case and ignoring the new incursion in Queensland (which may be of different origin), and assuming that each survey accurately identified the range limit, leads to a rate of spread of about $14 \mathrm{~km} \mathrm{yr}^{-1}$. This lower rate of spread is perhaps not surprising, as it is against the direction of the strong East Australian Current which Heyligers (2007) postulated as an impediment to coastal invasions moving northwards (though near-shore currents in this region are often northwards). Currents vary in direction and strength around the coast of Australia and with season. It is clear, however, that rates of invasion by Cakile are much slower than would be predicted from the rates of seed dispersal predicted from bottles and cards released offshore (Heyligers 2007). Flotation and viability of most seeds following submersion is very limited (Heyligers 2007). Nearshore movement is likely to be much more restricted than offshore, though seeds (and entire beaches) can be washed into the sea by storms.

Rodman's (1986) estimate of 40 years for the rate of replacement of Cakile edentula by Cakile maritima was based on a time series of the relative frequency of new collections of each species in the whole of South Australia and Victoria. The total number of specimens was very low, especially for Cakile edentula in the early years. Once again, the low sampling effort and reliance on chance collections results in extreme uncertainty in this estimate of 40 years. After Cakile maritima arrived at a site, its (perhaps) greater abundance would immediately make Cakile edentula harder to find, even if still present. However, even given these uncertainties, this rate of replacement at a geographic scale, on beaches where there often appears to be much empty space between mature plants, seems remarkably rapid. Within some locations, replacement would presumably have been even faster. Heyligers (1984) states that the replacement occurred over one or two decades along sections of coast. At the time of his paper both species could still be found together on beaches in southern NSW, 
whereas that is no longer the case less than thirty years later. Another example is Lord Howe Island, where the complete replacement occurred sometime after 1978 (even though all samples from that date and earlier were Cakile edentula, in the absence of proper surveys we cannot be certain that Cakile maritima had not already arrived).

Researchers in North America have investigated several possible factors causing the species replacement. Boyd \& Barbour(1993) found that Cakile maritima was a better competitor than Cakile edentula in a growth chamber but not in the field but dismissed direct competition as a mechanism of replacement because adult plants on a beach are typically widely spaced. They overlooked the fact that densities of seedlings can be extremely high at a fine scale (Keddy 1982; Donohue 1997) due to highly restricted dispersal of proximal fruit segments, though by maturity only a single plant often remains in these clumps. Cody \& Cody (2004) found a correlation between plant performance and distance between mature neighbours on a South Australian beach, suggesting that adult plants are competing. Instead of direct competition as the replacement mechanism, Boyd \& Barbour (1993) speculated that the estimated (up to) 18-fold greater lifetime fecundity in a Californian foredune meant that Cakile maritima would be more successful in colonising limited sites of suitable habitat through lottery competition (Chesson \& Warner 1981). Cakile maritima (or the genotypes of that species introduced into California) may be inherently more fecund than Cakile edentula, or as an outbreeder it may have been able to evolve more effectively to its new environment. Looking at a beach colonised by Cakile, one is struck by the large areas of apparently suitable habitat that are unoccupied. Given that entire sections of beach can be washed away in storms, greater fecundity would also make it more likely that Cakile maritima would be the species to recolonise from elsewhere along the coast after disturbance. Indeed, we suspect that many beaches, while supporting low densities of Cakile plants, may be sink populations while areas in which plants reach high densities (and undergo strong competition) may be source populations (Pulliam 1988: analysis of data from Boyd \& Barbour's study site (Boyd 1991) resulted in a net reproductive rate less than 1 , indicating that it was a sink population). The large variations in morphology between beaches that we report within a State may reflect chance recolonisations by a narrow range of morphotypes following complete population removal. Thus, the success of Cakile maritima may be enhanced by disturbance interacting with fecundity in a spatial context.

Alternatively, it is plausible that the disappearance of Cakile edentula could have been driven by an independent variable: the arrival of Cakile maritima was just coincidental. Indeed, Heyligers (2007) is of the opinion that Cakile edentula was declining in South Australia and western Victoria prior to the arrival of Cakile maritima. Given that Cakile edentula had successfully invaded Australian temperate, Mediterranean and sub-tropical climates, it is unlikely that climate change alone would have caused the demise of Cakile edentula over a large geographic range. If Cakile edentula spread from a single introduction, then this indicates either considerable phenotypic plasticity in relation to climate or a great ability to adapt (despite being an inbreeder). An alternative explanation is that a disease arrived after Cakile edentula (perhaps on Cakile maritima) and this was sufficient to make its net reproductive rate less than one. Both species are hosts to the fungal pathogen Alternaria brassicicola (Thrall et al. 2000): late in the season it is common in southern states to see populations of Cakile maritima in which every plant is blackened by the disease and they quickly die. The "Red Queen" hypothesis would predict that an inbreeder would be less able to adapt in response to evolution in the pathogenicity of the disease than an outbreeder (Antonovics et al. 2007). However, we have found Alternaria brassicicola to be present on herbarium specimens of Cakile edentula from before the arrival of the second host (although it is possible that more virulent pathotypes have arrived or evolved since). Bock (2008) found no difference between the plant species in susceptibility to five Cakile maritima-derived isolates of Alternaria brassicicola.

Perhaps the loss of Cakile edentula could have been caused indirectly by Cakile maritima, via another factor. For example, the arrival of Cakile maritima may have increased overall Cakile plant density, which in turn could have affected disease epidemiology. A larger population of diseased Cakile maritima plants, producing a greater pathogen load on Cakile edentula, could then have reduced the reproductive output of the latter, causing its net reproductive rate to be less than 1 . The rapid coevolution of the pathogen with Cakile maritima (Linde et al. 2010) may also have generated pathotypes that were particularly damaging to Cakile edentula (though see Bock 2008). Predation/herbivory may be another interactive factor. Seeds of both species can be heavily predated; however, Boyd (1988) excluded differential herbivory as the primary cause of the replacement in California.

\section{The role of hybridisation}

Putative hybrids are occasionally found in the field, supported by herbarium specimens, and hybrids can be produced in the glasshouse (Rodman 1974; C. Willis pers. comm. and our own unpublished work). In our experience these hybrids are most common on those Tasmanian beaches where Cakile maritima has only recently arrived and where Cakile edentula still dominates. Although we have observed a greater preference of pollinators for Cakile maritima in mixed populations (unpublished data), perhaps at low Cakile maritima relative frequency insects may move from one plant species to another more often than when Cakile maritima dominates populations. In many instances, however, we believe that the wide range of morphological variation in Cakile maritima (perhaps due to multiple introductions), together with a lack of familiarity with the now localised Cakile edentula, has misled some observers into concluding that hybrids are more common than is in fact the case. Eichler (1965), for example, stated that intermediates were common in South Australia, constituting a hybrid swarm, but his herbarium specimens are all within the range of variation expected for Cakile maritima in Europe. One web site (Weeds of Australia: Queensland Biosecurity Edition - Queensland Government, 2012) states that "intermediates between the two plants are common or dominant in some areas" but the basis of this statement is unclear (their photographs of Cakile edentula 
are clearly Cakile maritima). Several books (though not the major State or national floras) and web sites from Australia show pictures of "Cakile edentula" that fall clearly within the variation within Cakile maritima and outside the range of variation within Cakile edentula (e.g. Richardson et al. 2006; Harris et al. 2001; Queensland Government 2012). Perhaps these authors mistakenly assume that non-pinnatisect leaved plants must be either Cakile edentula or hybrids?

Cody \& Cody (2004) concluded from their survey of one South Australian population and one in British Columbia that in Australia hybridisation has played a major role in the demise of Cakile edentula. They suggest that the two species have produced an "introgressive swarm" in Australia, whereby the genes of Cakile edentula have mixed with Cakile maritima rather than one species simply replacing the other. The mechanism for the introgression resulting in a stable polymorphism was not proposed. Repeated back-crossing of selectively neutral hybrids to one of the parents (Cakile maritima) would probably have led to the rapid disappearance of traits from the other species rather than a stable polymorphism. A selective advantage in the hybrids, resulting in transgressive segregation, would require competition or another mechanism to account for the loss of the two parental species; hybrid species are often associated with new, rather than the parental, habitats (Rieseberg et al. 1999). In any case, if introgression has occurred in Australia, why has it not occurred in North America where the two species are also sympatric?

In addition to instances of putative hybrids with intermediate characters in the field and produced artificially, Cody \& Cody's argument is based on three observations: (i) morphological variation in Cakile maritima at Westlake Shores (sic), South Australia is much greater than in North America (no reference was made to variation in Europe); (ii) floral, fruit and leaf morphological characters at that site cover the range of variation documented for the two species; (iii) and leaf morphology at Westlake Shores is bimodal, "suggestive of genetic variability produced by introgression". It should be noted that the morphological descriptions and dimensions that they quote are only from Floras describing the species in their introduced range (Australia and North America): introductions in different countries may represent different regional morphotypes from the native range. Indeed, fruit shape variation in Cakile maritima is far greater in its native range than in North America (e.g. Ball 1964) and a different conclusion may have been reached if they had based their comparisons of Australian material on Flora Europaea (Tutin et al. 1993). Cody \& Cody's petal length measurements, which they compare to the ranges given in floras, were based only on the length of the flat, open part of the petal (the limb) rather than the entire petal used in those floras. Allowing for this difference in metrics, petal length data for Australian Cakile maritima also fall within the ranges reported for Cakile maritima in Europe [note that Flora Europaea gives petal lengths for Cakile maritima of 5-14 mm, whereas Cody \& Cody follow Australian floras in stating that petal length $>8 \mathrm{~mm}$ is diagnostic for the species; Rodman (1974) gives ranges of 8-14 mm for Cakile maritima and 4.6-9.7 $\mathrm{mm}$ for Cakile edentula]. In fact, the ranges of petal limb lengths for Cakile maritima in their Australian and Canadian sites were broadly similar. Petal widths, as Cody \& Cody show, are better diagnostic characters for the two species; however, they were not measured at their South Australian site.

The extreme leaf shapes that Cody \& Cody observed in Australia - entire and pinnatisect - can co-occur on beaches within Cakile maritima's home range as well as in different regions (Ciccarelli et al. 2010; Gandour et al. 2008; Mouterde 1970, Ross-Craig 1958; Tutin et al. 1993; Davy et al. 2006). Material from western North America, on which Cody \& Cody base their conclusions, appears to fit within a narrow part of the species variation (pinnatisect leaves with distinctly horned fruits), most likely from the Mediterranean (i.e. S. $m$. maritima). It is also worth noting that considerable variation in leaf and fruit morphology, including bimodality in leaf shape (Fig. 8), is found in Western Australia, where Cakile maritima first established and where Cakile edentula has never been confirmed west of Esperance. Bimodality may arise for reasons other than introgression: two genetically determined Cakile maritima leaf biotypes subject to environmental variation and scored on a linear scale, for example, would result in two modes. The scale may also include shapes that, though visually intermediate, are naturally uncommon.

In summary, although we cannot rule out introgression in Australia, the evidence in its favour is very weak. Variation resulting from intermixing of multiple introductions of different morphotypes of the same species, overlooked by Cody \& Cody as a possibility, or introduction from a single morphologically variable population, could just as easily explain their results and ours. It would also not require us to find a plausible reason why introgression has occurred on one continent and not the other, despite the fact that pollinators in British Columbia move readily between the two species. Clearly, however, molecular research is required to decide definitively between the alternatives.

\section{Issues with herbarium and survey data}

The data provided by herbaria are a wonderful resource, allowing us to investigate the history of the collection of species and biogeography. However, considerable caution is needed. Herbarium samples do not usually represent a structured survey; collection intensity varies considerably over time and between regions resulting in large gaps in time series. Herbarium records are also inevitably an over-estimate of the time of first appearance (they cannot be an under-estimate). Errors in the order of tens of decades and tens if not hundreds of kilometres are therefore possible in Australia. Herbarium data are increasingly being made available via electronic means, and may be combined with data unsupported by voucher specimens. The Atlas of Living Australia (ALA), Australia's Virtual Herbarium (AVH) and The Global Biodiversity Information Facility (GBIF), for example, have made it tantalisingly easy to access distribution data for ecological analysis (e.g. Gallagher et al. 2010; Aikio et al. 2010). It must be appreciated, however, that these databases do not constitute primary data. When checking herbarium sheets against databases, it is not uncommon to find errors in geographic coordinates as well as mis-identification of species, especially in difficult taxa. Such errors can be critical when trying to deduce invasion history and bioclimatic adaptation. We are concerned 
that many such studies do not "ground truth" their databasederived information. In the case of Cakile, it is common to find specimens attributed to the wrong species (see also Cousens \& Cousens 2011) and even after corrections have been made in herbaria it can take some time before these data flow through to databases such as ALA and AVH. Data from unvouchered sources (e.g. Natural Values Atlas, Tasmanian Government) may also contain potentially erroneous information which cannot be verified through examination of specimens. Given the acknowledged potential for misidentification of Cakile plants in Australia, we have chosen to exclude data from unvouchered sources for this study. We note that it was only by going back to the actual specimens were we able to deduce that Cakile maritima probably did not spread from Western Australia to the east (supported by recent molecular study - Ohadi et al. 2012): latitude, longitude and collection date were insufficient to determine the invasion history correctly.

Similarly, errors occur in survey data. In our surveys time constraints and accessibility meant that not all beaches were visited, so outlying populations may have been missed. Many beaches contained no plants of either species, or a low number of a single species, which may be because of severe recent disturbance episodes and failure to establish in the current season rather than due to a true absence of the species from that location. It is also plausible that if Cakile edentula was always scarce in a region, then the arrival of a dense Cakile maritima population would make it more difficult to find, even if its abundance did not change or it is still present at a low level. However, at a given beach the usually very narrow band occupied by the species was searched thoroughly for a distance of up to $500 \mathrm{~m}$ if one of the species had not been found; most plants were well past the seedling stage. Once the characteristic differences between the species are appreciated (colour, growth form, flower size), it is possible to distinguish them from a distance of over 5-10 m. We are also able to compare Heyligers' (unpublished) surveys in the late 1990s with our own and the results appear to be reasonably consistent.

Given the various sources of error, estimates of the time from first arrival of Cakile maritima to complete replacement of Cakile edentula within a region are particularly speculative. Herbarium collections rarely contain information on whether the other species of Cakile was present and in any case without material of both species from a site we cannot necessarily rely on collector identifications (given the common misidentification of the species). Semi-quantitative field surveys have now been conducted on two occasions by researchers fully aware of the species diagnostics and repetition of these surveys in future years will provide better estimates of rates of replacement, although the southern expansion of Cakile maritima appears to be rapidly reaching its conclusion. In Tasmania, monocultures of Cakile edentula can only be found in a small area in the southeast; annual monitoring of these beaches would be able to give a clear picture of the invasion dynamics as Cakile maritima arrives. Similarly, beaches in a $150 \mathrm{~km}$ stretch of coastline in eastern Tasmania could be selected to chart the hypothesised loss of Cakile edentula. In NSW there is a $270 \mathrm{~km}$ gap in the distribution of Cakile maritima occupied by Cakile edentula which would also be worth monitoring, along with the area north of Moreton Bay. If it is confirmed that the Queensland populations are a separate introduction - which we hypothesise on the base of morphological variation - then there is an opportunity to examine the population genetics that occurs in future as these come into contact with those moving northwards in NSW.

\section{Postscript on taxonomy}

Having tried to use Flora Europaea and Ball's (1964) drawings to distinguish Cakile maritima subspecies, we became increasingly unconvinced by their diagnostic keys. Observations by one of us (RC) in northern and southern Spain, and a survey of photographs on the internet and botanical drawings in regional European floras and plant picture books, suggest that keys may not adequately represent the geographic variation. We suggest that a review is needed, preferably sampling within and between populations (as in our study) rather than relying on herbaria, to determine how morphological variation correlates with regional molecular data. Moreover, there remains some confusion in the naming of the subspecies, particularly with regard to maritima, integrifolia and aegyptiaca. This requires the attention of a taxonomist with access to possible lectotypes.

\section{Acknowledgements}

We thank the curators of AD, BRI, CANB, MEL, NSW and PERTH for their help in accessing material and data bases. Special thanks go to James Rodman, who provided patient responses to our many questions about Cakile taxonomy, and to Petrus Heyligers, who provided unpublished survey data and personal observations. We have merely built on their earlier work. Thanks also to Brendan Lepschi for comments on an earlier version of the manuscript.

\section{References}

Aikio, S., Duncan, R.P. \& Hulme, P.E. (2010) Lag-phases in alien plant invasions: separating the facts from the artefacts. Oikos 119: 370-378.

Antonovics, J., Thrall, P.H., Burdon, J.J. \& Laine, A.-L. (2011) Partial resistance in the Linum-melampsora host-pathogen system: does partial resistance make the red queen run slower? Evolution 65: 512-522.

Ball, P.W. (1964) A revision of Cakile in Europe. Feddes Repertorium 69: 35-40.

Barbour, M.G. \& Rodman, J.E. (1970) Saga of the West Coast sea-rockets: Cakile edentula ssp. californica and C. maritima. Rhodora 72: 370-386.

Bock, C.H. (2008) The effect of Alternaria brassicicola infection on the reproductive fitness of the naturally occurring littoral ruderals Cakile maritima and C. edentula. Australian Plant Pathology 37: 569-580

Boyd, R.S. \& Barbour, M.G. (1993) Replacement of Cakile edentula by $C$. maritima in the strand habitat of California. American Midland Naturalist 130: 209-228.

Boyd, R.S. (1988) Herbivory and species replacement in the west coast searockets (Cakile: Brassicaceae). American Midland Naturalist 119: 304-317.

Boyd, R.S. (1991) Population biology of west coast Cakile maritima: Effects of habitat and predation by Peromyscus maniculatus. Canadian Journal of Botany 69: 2620-2630. 
Castroviejo, S. (ed.) 1996. Flora Iberica, Volume IV: CruciferaeMonotropaceae. (Real Jardín Botánico: Madrid).

Chesson, P.L. \& Warner, R.R. (1981) Environmental variability promotes coexistence in lottery competitive systems. American Naturalist 117: 923-943.

Ciccarelli, D., Balestri, M., Pagni, A.M. \& Forino, L.M.C. (2010) Morpho-functional adaptations in Cakile maritima Scop. subsp. maritima: comparation of two different morphological types. Caryologia 63: 411-421.

Clark, J.S., Lewis, M. \& Horvath, L. (2001) Invasion by extremes: population spread with variation in dispersal and reproduction. American Naturalist 157: 537-54.

Clausing, G., Vickers, K. \& Kadereit, J.W. (2000) Historical biogeography in a linear system: genetic variation of Sea Rocket (Cakile maritima) and Sea Holly (Eryngium maritimum) along European coasts. Molecular Ecology 9: 1823-1833.

Cody, M. L. \& Cody T. W. D. (2004) Morphology and spatial distribution of alien sea-rockets (Cakile spp.) on South Australian and western Canadian beaches. Australian Journal of Botany 52: 175-183.

Cousens, R.D. \& Cousens, J.M. (2011) Invasion of the New Zealand Coastline by European Sea-Rocket (Cakile maritima) and American Sea-Rocket (Cakile edentula). Invasive Plant Science and Management 4: 260-263.

Cousens, R., Dytham, C. \& Law, R. (2008) Dispersal in Plants: A population perspective. (Oxford University Press, Oxford)

Cousens, R., Kennedy, D., Maguire, G. \& Williams K. (2013) Just how bad are coastal weeds: Assessing the geo-ecopsycho-socio-economic impacts. (Rural Industries Research \& Development Corporation, Canberra).

Davy, A.J., Scott, R. \& Cordazzo, C.V. (2006) Biological flora of the British Isles: Cakile maritima Scop. Journal of Ecology 94: 695-711.

Donohue K (1997) Seed dispersal in Cakile edentula var. lacustris : decoupling the fitness effects of density and distance from the home site. Oecologia 110: 520-527.

Eichler, H. (1965) Supplement to J. M. Black's Flora of South Australia (second edition, 1943-1957), p. 162. (Government Printer, Adelaide).

Gallagher, R.V., Beaumont, L.J., Hughes, L. \& Leishman, M.R. (2010) Evidence for climatic niche and biome shifts between native and novel ranges in plant species introduced to Australia. Journal of Ecology 98: 790-799.

Gandour, M., Hessini, K. \& Abdelly, C. (2008) Understanding the population genetic structure of coastal species (Cakile maritima): seed dispersal and the role of sea currents in determining population structure. Genetics Research, Cambridge 90: 167-178.

Harris, S., Buchanan, A. \& Connolly, A. (2001) One Hundred Islands: The Flora of the Outer Furneaux. (Department of Primary Industries, Water and Environment, Hobart).

Hewson, H.J. (1982) Cakile. In: Flora of Australia Volume 8 Lecythidales to Batales, pp.251-252. (Australian Government, Canberra).

Heyligers, P.C. (1984) Beach invaders. Australian Natural History 21: 212-214.

Heyligers, P.C. (1989) Strandline plants: History in the making (and you are invited to take part in it). Nature in Eurobodalla 3: 34-36.

Heyligers, P.C. (2007) The role of currents in the dispersal of introduced seashore plants around Australia. Cunninghamia 10: $167-188$.

Kadereit, J.W., Arafeh, R., Somogyi, G. \& Westberg E. (2005) Terrestrial growth and marine dispersal? Comparative phylogeography of five coastal plant species at a European scale. Taxon 54: 861-876.
Keddy, P.A. (1982) Population ecology on an environmental gradient: Cakile edentula on a sand dune. Oecologia 52: 348355.

Linde, C.C., Liles, J.A., \& Thrall, P.H. (2010) Expansion of genetic diversity in randomly mating founder populations of Alternaria brassicicola infecting Cakile maritima in Australia. Applied Environmental Microbiology 76: 1946-1954.

Marhold, K. (2011) Brassicaceae. In: Euro+Med Plantbase - the information resource for Euro-Mediterranean plant diversity. http://ww2.bgbm.org/EuroPlusMed/PTaxonDetail.asp?NameI $\mathrm{d}=14226 \& \mathrm{PTRefFk}=7200000$ accessed 3 January 2013 .

Mouterde, P. (1970) Nouvelle Flore du Liban et de la Syrie, Volume 2. (Beyrouth: Lebanon).

Ohadi, S., Ades, P.K., Cousens, R.D. \& Ford, R. (2012) Genetic variation in invasive populations of sea rocket (Cakile maritima) in southern coastal habitats of Australia. Proceedings of the $18^{\text {th }}$ Australasian Weeds Conference, pp. 373-374.

Okada, M., Lyle M., \& Jasieniuk, M. (2009) Inferring the introduction history of the invasive apomictic grass Cortaderia jubata using microsatellite markers. Diversity and Distributions $15: 148-157$.

Pickard, J. (1984) Exotic plants on Lord Howe Island: distribution in space and time, 1853-1981. Journal of Biogeography 11: 181-208.

Pobedimova, P.G. (1963) A general survey of the genus Cakile Mill. Botanicheskii Zhurnal 48: 1762-1765 [in Russian].

Pulliam, H.R. (1988) Sources, sinks and population regulation. American Naturalist 132: 652-661.

Queensland Government (2012) http://keyserver.lucidcentral.org/ weeds/data/03030800-0b07-490a-8d04-0605030c0f01/media/ html/Cakile_edentula.htm, accessed 7 Sept 2012.

Rich, T.C.G. (1992) Crucifers of Great Britain and Ireland. (BSBI Handbook No. 6. Botanical Society of the British Isles, London).

Richardson, F.J., Richardson, R.G. \& Shepherd, R.C.H. (2011) Weeds of the South-East: An identification guide for Australia, second edition. (R.G. \& F.J. Richardson, Meredith, Victoria).

Rieseberg, L.H., Archer, M.A. \& Wayne, R.K. (1999) Transgressive segregation, adaptation and speciation. Heredity 83 : 363-372.

Rodman, J.E. (1974) Systematics and evolution of the genus Cakile (Cruciferae). Contributions of the Gray Herbarium, Harvard University 205: 3-146.

Rodman, J.E. (1976) Differentiation and migration of Cakile, (Cruciferae): seed glucosinolate evidence. Systematic Botany 1: $137-148$

Rodman, J.E. (1986) Introduction, establishment and replacement of sea-rockets (Cakile, Cruciferae) in Australia. Journal of Biogeography 13: 159-171.

Ross-Craig, S. (1958) Drawings of British Plants. (G. Bell \& Sons, London).

Sauer, J.D. (1988) Plant Migration: The dynamics of geographic patterning in seed plant species. (University of California Press, Berkeley).

Thrall, P.H., Young, A.G. \& Burdon, J.J. (2000) An analysis of mating structure in populations of the annual sea rocket, Cakile maritima (Brassicaceae). Australian Journal of Botany 48: 731-738.

Tutin, T.G., Heywood, V.H., Burges, N.A., Valentine, D.H., Walters, S.M. \& Webb, D.A. (eds) (1993) Flora Europaea. (Cambridge University Press, Cambridge)

Manuscript accepted 3 June 2013 